\title{
BMJ Open Loss of GD1-positive Lactobacillus correlates with inflammation in human lungs with COPD
}

\author{
Marc A Sze, ${ }^{1}$ Soraya Utokaparch, ${ }^{1}$ W Mark Elliott, ${ }^{1}$ James C Hogg, ${ }^{1}$ \\ Richard G Hegele ${ }^{2}$
}

To cite: Sze MA,

Utokaparch S, Elliott WM, et al. Loss of GD1-positive Lactobacillus correlates with inflammation in human lungs with COPD. BMJ Open 2015:5:e006677. doi:10.1136/bmjopen-2014006677

- Prepublication history and additional material is available. To view please visit the journal (http://dx.doi.org/ 10.1136/bmjopen-2014006677).

Received 22 September 2014 Revised 9 January 2015 Accepted 13 January 2015

\section{(a) CrossMark}

${ }^{1}$ Departments of Medicine and Pathology and Laboratory Medicine, Centre for Heart Lung Innovation, Providence Heart-Lung Institute at St Paul's Hospital, University of British Columbia, Vancouver, British Columbia, Canada

${ }^{2}$ Department of Laboratory Medicine and Pathobiology, University of Toronto,

Ontario, Canada

Correspondence to

Dr Marc A Sze;

Marc.Sze@hli.ubc.ca

\section{ABSTRACT}

Objectives: The present study assesses the relationship between contents of GD1 (glycerol dehydratase)-positive Lactobacillus, presence of Lactobacillus and the inflammatory response measured in host lung tissue in mild to moderate chronic obstructive pulmonary disease (COPD). We hypothesise that there will be a loss of GD1 producing Lactobacillus with increasing severity of COPD and that GD1 has anti-inflammatory properties.

Setting: Secondary care, 1 participating centre in Vancouver, British Columbia, Canada.

Participants: 74 individuals who donated non-cancerous portions of their lungs or lobes removed as treatment for lung cancer (normal lung function controls $(\mathrm{n}=28)$, persons with mild (GOLD 1) $(n=21)$ and moderate (GOLD 2) COPD $(n=25))$.

Outcome measures: Primary outcome measure was GD1 positivity within each group and whether or not this impacted quantitative histological measures of lung inflammation. Secondary outcome measures included Lactobacillus presence and quantification, and quantitative histological measurements of inflammation and remodelling in early COPD.

Results: Total bacterial count $(p>0.05)$ and prevalence of Lactobacillus $(p>0.05)$ did not differ between groups. However, the GD1 gene was detected more frequently in the controls $(14 \%)$ than in either mild $(5 \%)$ or moderate $(0 \%)$ COPD $(p<0.05)$ samples. Macrophage and neutrophil volume fractions $(0.012 \pm 0.005($ mean $\pm S D)$ vs $0.026 \pm 0.017$ and $0.005 \pm 0.002$ vs $0.015 \pm 0.014$ respectively) in peripheral lung tissue were reduced in samples positive for the GD1 gene ( $p<0.0035)$.

Conclusions: A reduction in GD1 positivity is associated with an increased tissue immune inflammatory response in early stage COPD. There is potential for Lactobacillus to be used as a possible therapeutic, however, validation of these results need to be completed before an anti-inflammatory role of Lactobacillus in COPD can be confirmed.

\section{INTRODUCTION}

Chronic obstructive pulmonary disease (COPD) is a worldwide public health problem that affects approximately $10 \%$ of persons over

\section{Strengths and limitations of this study}

- Study performed directly on human lung tissue.

- Data show a novel potential mechanism for Lactobacillus in chronic obstructive pulmonary disease (COPD) pathogenesis.

- Patient population is well controlled and stratified between disease groups.

- Lactobacillus is tested directly on tissue avoiding potential contamination from the mouth and upper airways.

- Small number of total positive GD1 (glycerol dehydratase) samples.

40 years of age ${ }^{1}$ and is predicted to become the fourth leading cause of death in the USA by $2020 .{ }^{2}$ Previous studies have shown an association between the decline in forced expiratory volume in $1 \mathrm{~s}\left(\mathrm{FEV}_{1}\right)$ and the infiltration of peripheral lung tissue by neutrophils, macrophages, CD4+ and CD8+ $\mathrm{T}$ cells, and B-cell lymphocytes that have an increasing tendency to form tertiary lymphoid follicles in lungs from persons with severe (GOLD 3) and very severe (GOLD 4) COPD. ${ }^{3}$ These data provide evidence that an innate and adaptive inflammatory immune response may be present, and initially begins in early grade COPD. However, what the target is for this adaptive immune response is not yet known. Evidence has been shown to support a potential autoimmune mechanism against elastin. ${ }^{4}$ However, others believe that it could be environmental causes such as bacteria that drive this immune response. ${ }^{5}$ Recently, several groups have suggested that the lung itself is not sterile and that there is a detectable bacterial microbiome present. ${ }^{6-10}$ They have also shown that this bacterial microbiome changes in COPD. ${ }^{79}$ It may be possible that some of these bacteria could be potential targets of the adaptive immune response observed in COPD while others, in contrast, may have beneficial roles. 
One of these previous reports on the bacterial microbiome in lung tissue identified Lactobacillus as a potential bacteria that could discriminate between control lung tissue and COPD GOLD $4 .^{9}$ In order to investigate how this might contribute to the pathogenesis of COPD, this study examines the host response to differences between Lactobacillus-positive and Lactobacillus-negative samples as well as on Lactobacillus spp, either positive or negative, for the bacterial glycerol dehydratase (GD1) gene. This gene is most commonly found on plasmids within the Lactobacillus reuteri and along with potassium and 1,2-propanediol converts glycerol to reuterin via a dehydration reaction mechanism. ${ }^{11}$ Reuterin is a broadspectrum antibiotic of which the mechanism of action is postulated to act via an oxidative stress mechanism. ${ }^{12}$ Expansion of Lactobacillus is associated with a reduction in reuterin production, ${ }^{13}$ potentially due to quorum sensing. This means that less Lactobacillus will be able to convert glycerol to the broad-spectrum antibiotic reuterin when these bacteria are found in high abundance. ${ }^{14} 15$ Based on this information along with the previous findings within the lung tissue bacterial microbiome we hypothesise that there will be a loss of GD1-producing Lactobacillus with increasing severity of COPD and that GD1 has anti-inflammatory properties.

\section{METHODS}

\section{Preliminary data sample group}

Samples from these individuals were from a previously published study ${ }^{9}$ and the processing, tissue sampling methods and DNA extraction methods have already been published. Demographic information was also previously published but in brief it consisted of tissue from eight non-smokers, eight smokers and eight COPD GOLD 4. The non-smokers and smokers had normal lung function without obstruction. Their $\mathrm{FEV}_{1}$ percentage predicted value was $88.8 \pm 13.4$ and $94.3 \pm 15.3$, respectively, while their $\mathrm{FEV}_{1}$ /forced vital capacity (FVC) was 80.80 \pm 4.82 and $76.65 \pm 5.07$, respectively. The COPD GOLD 4 group had an $\mathrm{FEV}_{1}$ of $15.4 \pm 2.4$ and an $\mathrm{FEV}_{1} / \mathrm{FVC}$ of $26.83 \pm 7.85$. There was no significant difference between pack years smoked between the smokers $(46.00 \pm 12.24)$ and COPD GOLD 4 group $(38.83 \pm 14.97)$.

\section{Early COPD group}

Tissue collection

The methods used to collect and preserve lung tissue for both PCR and quantitative PCR (qPCR) are previously published. ${ }^{3} 9^{9} 16 \quad 17$ Briefly, lung tissue samples donated by 74 individuals, treated for lung cancer by either lobectomy or pneumonectomy, were entered into this study. All 74 individuals provided informed consent for the use of their lung tissue in this study under conditions approved by the appropriate committees of all the institutions involved. The postbronchodilator $\mathrm{FEV}_{1}$ and $\mathrm{FEV}_{1} / \mathrm{FVC}$ measurements made during the preoperative assessment of lung function were used to assign these donated tissues to 'At Risk' controls ( $\mathrm{n}=28)$, mild COPD (GOLD 1) $(\mathrm{n}=21)$ and moderate COPD (GOLD 2) $(n=25)$. Three of the 74 individuals ( 2 in the control group and 1 in the GOLD 1 group) had used inhaled corticosteroids and all 74 were free from clinically apparent respiratory infection at the time of surgery. No recent antibiotic treatment information was recorded in these individuals.

\section{Tissue processing}

Following completion of the pathological examination, each lung specimen was inflated, frozen and stored at $-80^{\circ} \mathrm{C}$ as previously described. ${ }^{3}{ }^{1} 17$ The specimen was kept frozen on dry ice while being cut from apex to base into $2 \mathrm{~cm}$ thick slices and a drill press with a sharpened hollow cylinder removed cores of tissue from each lung slice. Two tissue cores were examined for $27 / 28$ cases in the control group, 19/21 cases in the GOLD 1 and 25/ 25 cases in the GOLD 2 groups. In the remaining three individuals' samples only one tissue core was examined. Five series of 20 consecutive frozen sections were cut from each tissue core and sections $1-5,8-12$ and 14-18 were allocated for DNA extraction, and sections $6-7,13$ and 19-20 allocated to coded glass slides for histological staining.

\section{qPCR for total bacteria and Lactobacillus}

For all qPCR assays, a correction factor to account for plate variation was applied as described in the online supplementary material. A previously described assay was used to determine the total bacterial load and spanned the $16 \mathrm{~S}$ hypervariabe V2 region. One modification was made to the analysis in that total bacteria were expressed as $16 \mathrm{~S} / \mathrm{ng}$ of DNA instead of bacteria/Rpp $40 .{ }^{9}$ The assay for total Lactobacillus has been previously reported and no modifications were made. ${ }^{9} 18$ The forward primer sequence was 5-ACG AGT AGG GAA ATC TTC CA-3 and the reverse primer sequence was 5-CAC CGC TAC ACA TGG AG-3, and was designed to target all species in the genera Lactobacillus and Lactococcus. The values for total Lactobacillus were expressed as a percentage of total $16 \mathrm{~S}$ bacteria and were obtained from normalisation to total 16S (eg, (Lactobacillus value/16S value) $\times 100$ ). The standard curve formulas for both assays can be found in the online supplementary table S1.

\section{PCR for GD1}

A 40-cycle PCR was performed on all DNA samples and yielded an approximately $560 \mathrm{bp}$ sized band resolved on a $1 \%$ agarose gel. The forward primer was 5-GTTCAGTCCGCCGCATATC-3 and for the reverse primer 5-GCCGCTCTTCGTGGATTTC-3. The cycling conditions have been published previously. ${ }^{19}$ If at least one of the two samples from an individual tested positive, then the individual was considered positive for bacteria containing the GD1 gene. 


\section{Quantitative histology}

Sections on coded glass slides were stained for macrophages, neutrophils, eosinophils, natural killer (NK) cells, dendritic cells and follicular dendritic cells, B lymphocytes, CD8+ $\mathrm{T}$ lymphocytes and CD4+ T lymphocytes. A more detailed breakdown of the staining can be found in online supplementary table S2. ImagePro Plus software V. 4.0 (MediaCybernetics Inc, Bethesda, Maryland, USA) was used to compute the volume fraction $(\mathrm{Vv})$ of the tissue taken up by specifically stained inflammatory cells in the small airway wall tissue, using established point counting methods. ${ }^{3}$ Intraobserver and interobserver error for the quantitative histology was assessed (see online supplementary figures S1 and S2) and there was a good correlation between both $\left(\mathrm{R}^{2}\right.$ of 0.9046 and 0.9485 , respectively).

\section{Data analysis}

Data from a previously published data set that consisted of non-smokers $(n=8)$, smokers $(n=8)$ and COPD GOLD $4(\mathrm{n}=8)^{9}$ were first analysed for the prevalence of GD1. Subsequent analysis was performed on the current data set for the role of Lactobacillus in early COPD. A multivariate analysis was performed to assess associations between the bacterial load, relative abundance of Lactobacillus, inflammatory cell $\mathrm{Vv}$ and airway wall thickness. Where applicable, the mean $\pm \mathrm{SD}$ for the different groups was listed. Categorical data comparing the distribution of Lactobacillus detection through increasing disease severity and GD1 detection throughout GOLD stage utilised a $\chi^{2}$ test. Analysis of GD1-positive versus GD1-negative samples utilised multiple comparisons and a Bonferroni correction was applied. All other data utilised the Student $t$ test for significance testing. A $p$ value of $<0.05$ was considered statistically significant unless otherwise stated due to Bonferroni correction. Multivariate analysis was performed and a correlation was considered significant if it was below a $p$ value of 0.05 .

\section{RESULTS}

\section{Early COPD group demographics}

Table 1 shows there was no significant difference in age, gender or smoking history between the three groups of individuals $(\mathrm{p}>0.05)$, and the difference in $\mathrm{FEV}_{1} / \mathrm{FVC}$ and $\mathrm{FEV}_{1}$ percentage predicted shown in table 1 is consistent with their status as either control, mild or moderate COPD.

\section{qPCR for total bacteria and Lactobacillus}

Online supplementary table S3 displays the location breakdown within the lung of each respective tissue sample. There was no difference between the top, middle and lower thirds of the lung with respect to total bacteria ( $p$ values ranging from 0.30 to 0.90 ; see online supplementary table S4 and figure S3). Since no significant difference was found between the two samples from each individual they were averaged together for all subsequent analysis. There was no significant difference ( $p>0.05$ ) between the sample groups based on total $16 \mathrm{~S} / 100 \mathrm{ng}$ of DNA (see online supplementary figure S4). The control group had an average value of $22.0 \pm 21($ mean \pm SD), the GOLD 1 group had $20.9 \pm 13.2$ and the GOLD 2 group had 15.5 $\pm 16.816 \mathrm{~S} / 100 \mathrm{ng}$ of DNA, respectively. There was also no difference in total bacteria with respect to any drug use ( $p>0.05$; see online supplementary figure S5) or steroid use only (data not shown).

There was no significant difference between the three sample groups in the percentage of total Lactobacillus after Bonferroni correction ( $p>0.05$; see online supplementary figure S6). The percentage of total Lactobacillus for the control group was $8.7 \% \pm 15.0 \% \quad($ mean \pm SD $)$, $2.5 \% \pm 3.8 \%$ for the GOLD 1 group and $8.1 \% \pm 11.6 \%$ for the GOLD 2 group. There was no difference in the relative abundance of Lactobacillus based on any drug use or steroid use only (data not shown). Further, there was no significant difference in clinical characteristics (lung function, smoking history, age and gender) between Lactobacillus-positive and Lactobacillus-negative individuals (see online supplementary table S5).

\section{PCR for GD1}

Preliminary data showed that there was a clear decrease in the prevalence of GD1-producing Lactobacillus in the COPD GOLD 4 lung tissue when compared to both the non-smoking and smoking controls $(\mathrm{p}<0.05$; figure $1 \mathrm{~A})$. Following up on this data in the early COPD data set a total of $5 / 74(7 \%)$ of samples tested positive for the GD1 gene and $4 / 5(80 \%)$ of these individuals also

Table 1 Clinical characteristics of the sample groups (average \pm SD)

\begin{tabular}{llll}
\hline & Controls $(\mathbf{n = 2 8})$ & GOLD 1 $(\mathbf{n = 2 1})$ & GOLD 2 $(\mathbf{n = 2 5})$ \\
\hline Age & $65.7 \pm 9.6$ & $66.0 \pm 8.9$ & $63 \pm 9.2$ \\
Gender (M:F:unknown) & $16: 11: 1$ & $14: 7: 0$ & $17: 8: 0$ \\
Smoking history (cigarette-years) & $895.4 \pm 622.8$ & $1061.8 \pm 410.5$ & $945.0 \pm 555.7$ \\
FEV $/$ FVC & $77.4 \pm 4.9$ & $64.3 \pm 4.3^{*}$ & $62.0 \pm 7.0 \dagger$ \\
FEV 1 (percentage predicted) & $100.0 \pm 12.5$ & $89.9 \pm 9.0 \ddagger$ & $69.0 \pm 6.6 \dagger$ \\
\hline
\end{tabular}

${ }^{*} p<0.0001$ between controls versus GOLD 1 .

$t p<0.0001$ between controls versus GOLD 2.

$\ddagger \mathrm{p}<0.0001$ between GOLD 1 versus GOLD 2.

$\mathrm{FEV}_{1}$, forced expiratory volume in $1 \mathrm{~s}$; FVC, forced vital capacity. 

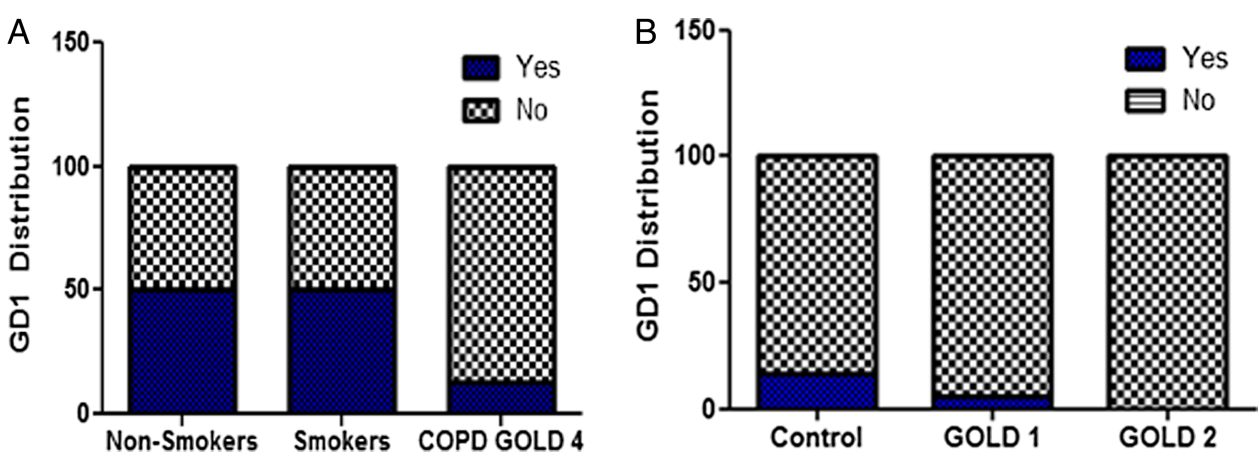

Figure 1 (A) GD1 (glycerol dehydratase) distribution in the preliminary data set displayed as a percentage; non-smokers $(n=8)$, smokers $(n=8)$, and chronic obstructive pulmonary disease (COPD) GOLD $4(n=8), p>0.05$ between groups. (B) GD1 distribution displayed as a percentage. The graph showing the percentage of GD1-positive individuals in controls, GOLD 1 and GOLD 2.

tested positive for Lactobacillus. There was a significant decrease in the individuals who tested positive for the GD1 gene as the disease severity increased $(p<0.05$; figure 1B). A total of $14 \%$ of individuals were positive for GD1 in the control group versus $5 \%$ and $0 \%$ in the GOLD 1 and GOLD 2 groups, respectively (figure 1B). There was no significant difference in steroid use, bronchodilator use or use of both types of drugs between those who were GD1 positive and those who were GD1 negative $(p>0.05)$.

\section{Quantitative histology}

The two samples from each individual were averaged for the final $\mathrm{Vv}$ measurement data used for all inflammatory cells. A complete figure of the quantitative histology results by GOLD grade is in the online supplementary figure S7. The multivariate analysis on all the $\mathrm{Vv}$ small airway measurements as well as the total bacterial $16 \mathrm{~S}$ and percentage of total Lactobacillus showed that the $\mathrm{Vv}$ of CD1a+ cells correlated with the percentage of total Lactobacillus ( $\mathrm{r}=0.27, \mathrm{p}=0.038$; table 2). These CD1a+ dendritic cells were also positively correlated with CD35 + follicular dendritic cells $(\mathrm{r}=0.39, \mathrm{p}=0.009)$ and CD8+ $\mathrm{T}$ cells $(\mathrm{r}=0.27, \mathrm{p}=0.04)$. Total $16 \mathrm{~S}$ bacterial load positively correlated with CD21+ follicular dendritic cells $(\mathrm{r}=0.30, \mathrm{p}=0.013$; table 2). These CD21+ follicular dendritic cells were also positively correlated with NK-1 cells $(r=0.32, p=0.013)$. The strongest correlation from the multivariate analysis was between $\mathrm{CD} 4+\mathrm{T}$ cells and CD68+ macrophages $(\mathrm{r}=0.44, \mathrm{p}=0.001)$.

The inflammatory cell $\mathrm{Vv}$ was then investigated between GD1-positive versus GD1-negative individuals (figure 2). There was a significant reduction in the $\mathrm{Vv}$ of CD68+ macrophages and neutrophils in GD1-positive versus GD1-negative groups $(\mathrm{p}<0.0035$; figure $2 \mathrm{~B}, \mathrm{C})$. This difference held, when only control samples were analysed, for CD68+ macrophages (see online supplementary figure $\mathrm{S} 8, \mathrm{p}<0.05)$ but not for neutrophils $(\mathrm{PMN}$ ) (see online supplementary figure $\mathrm{S9}, \mathrm{p}>0.05$ ). There was no difference in inflammatory cell $\mathrm{Vv}$ in the small airways with steroid (data not shown) or with any drug use (see online supplementary figure S3).

\section{DISCUSSION}

The present results confirm earlier reports showing no difference in total bacteria within the microbiome between control and COPD lungs, and extend them by showing that this applies to tissue in mild to moderate COPD. ${ }^{9}$ It also shows that although no detectable difference in total Lactobacillus could be made between controls, GOLD 1 and GOLD 2 differences in the genotypic makeup of the Lactobacillus could be found in the loss of GD1 positivity in mild and moderate COPD. Furthermore, Lactobacillus was found to have a positive correlation with CDlat dendritic cells suggesting that Lactobacillus may influence the host response through

Table 2 Significant comparisons from multivariate analysis of all measurements made on lung tissue

\begin{tabular}{lllll}
\hline All samples & & & & \\
\hline Variable & By variable & $\mathbf{n}$ & Significant probability & Correlation \\
\hline CD1a+ dendritic cell & Lacto/total (16S) & 60 & 0.038 & 0.268 \\
CD21+ follicular dendritic cell & 16S total & 66 & 0.013 & 0.304 \\
CD35+ follicular dendritic cell & CD1a+ dendritic cell & 45 & 0.009 & 0.386 \\
NK-1 & CD21+ follicular dendritic cell & 59 & 0.013 & 0.321 \\
CD4 T cell & CD68+ macrophage & 51 & 0.001 & 0.445 \\
CD8 T cell & CD1a+ dendritic cell & 56 & 0.046 & 0.268 \\
CD79a+ B cell & CD4 T cell & 51 & 0.039 & 0.290 \\
NK, natural killer. & & & &
\end{tabular}




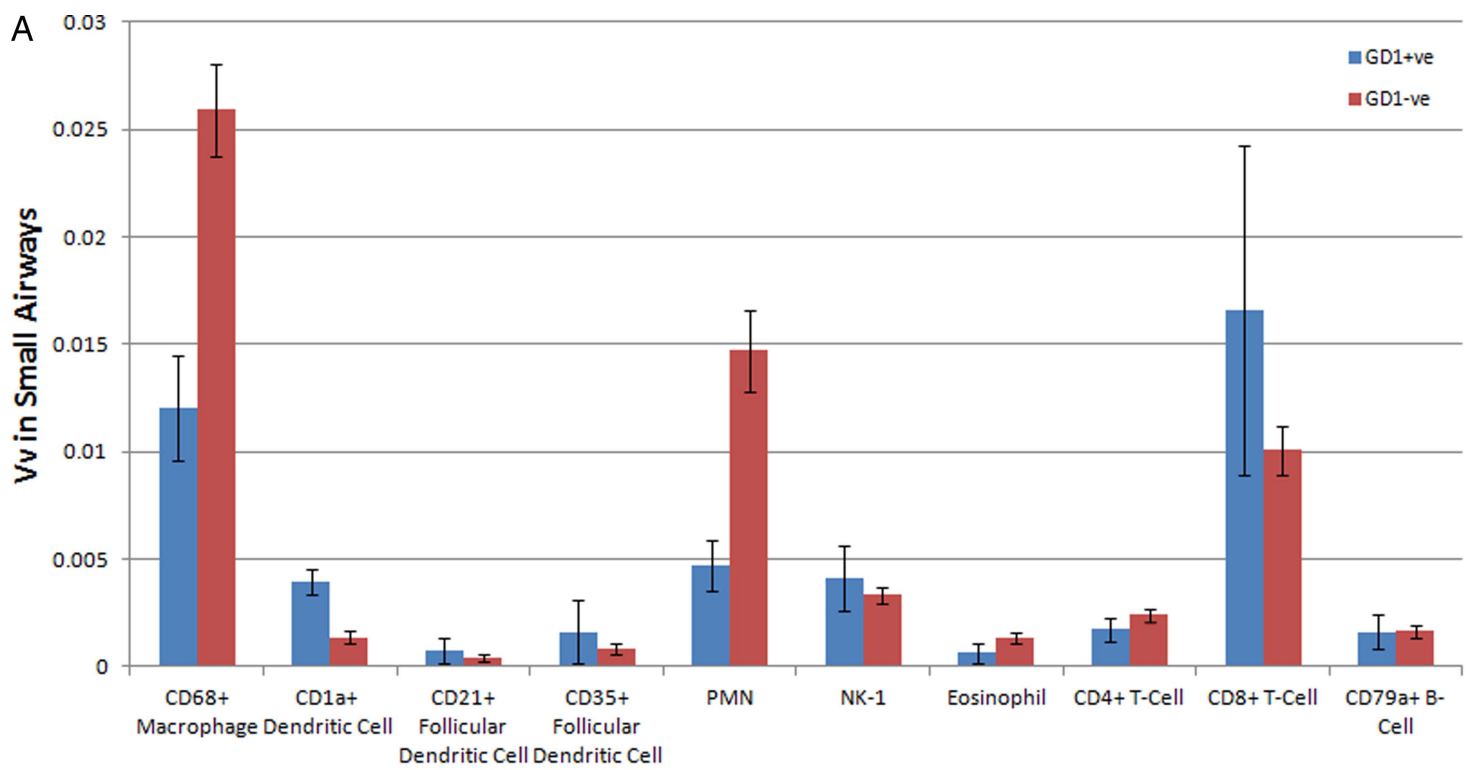

B

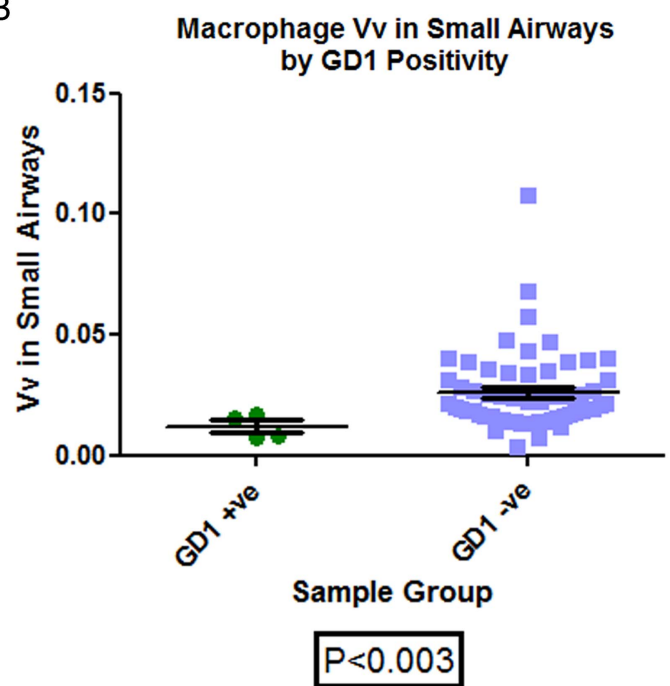

C

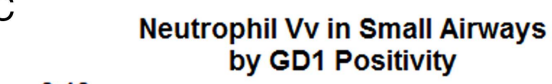
by GD1 Positivity

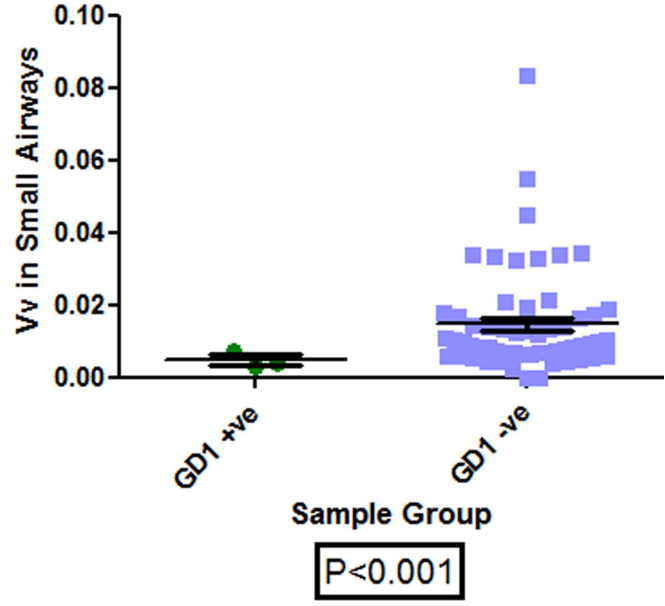

Figure 2 (A) Inflammatory cell volume fraction in GD1 (glycerol dehydratase)-positive and GD1-negative samples. No significant difference was seen between the adaptive immune cell Vv and GD1 ( $p>0.05)$. A significant difference was seen in the Vv of macrophages and neutrophils based on GD1 positivity $(p<0.0035)$. (B) Small airway Vv of macrophages by GD1 positivity $(p<0.0035)$. (C) Small airway Vv neutrophils by GD1 positivity $(p<0.0035)$.

these cells. Finally, this study also shows that GD1-positive individuals have lower macrophage and neutrophil Vv than GD1-negative individuals. Overall, this data supports the hypothesis that GD1-positive Lactobacillus may have an anti-inflammatory role in the pathogenesis of COPD.

These observations are of particular interest because of a previous report by Forsythe et $a l^{20}{ }^{20}$ who showed that in mice sensitised to albumin, oral treatment with GD1-positive $L$. reuteri prior to challenging their airways with albumin resulted in a reduction in macrophage and neutrophil infiltration into their lung tissue, and reduced the cellular and inflammatory mediator content of their broncheoalveolar lavage (BAL) fluid compared with controls treated with saline alone. ${ }^{20}$ In addition, these investigators subsequently reported that the nonspecific CD4 (+) CD25 (+) Foxp3 (+) regulatory T cells exerted a potent immunoregulatory action on the response to challenge by a specific antigen. ${ }^{21}$ These observations clearly suggest the possibility that GD1-positive Lactobacilli induce immunoregulatory mechanisms capable of controlling the host immune response in mice. Our study builds on these previous observations by investigating Lactobacillus in human lung tissue, and is consistent with Forsythe $e t a l$ s macrophage and neutrophil data.

The preliminary data that were investigated suggest that, as in GOLD 1 and GOLD 2 grade disease, GOLD 4 also has a significant reduction in GD1-positive individuals versus controls. This would imply that reduction in GD1 positivity occurs early on in disease and could be a contributing factor to the increased inflammation seen as disease progresses. ${ }^{3}$ More studies designed to investigate Lactobacillus across all grades of disease will need to 
be completed to elucidate the true scope to which this genus can influence the progression of COPD.

Previous studies have shown that CD8+ $\mathrm{T}$ cells are important in the progression of COPD. ${ }^{22}$ The correlation between CD1a+ dendritic cells and CD8+ T cells along with the CDla+ dendritic cell correlation with Lactobacillus provides a possible mechanism by which these bacteria may exert their action in COPD. Although, in the early COPD data set, there was a significant reduction in GD1-positive macrophage and neutrophil $\mathrm{Vv}$ when compared to the GD1-negative group, no correlations with macrophages or neutrophils could be found with respect to Lactobacillus. This suggests that the effect between these specific inflammatory cells and GD1-positive Lactobacillus may not be a simple linear correlation and may act through other inflammatory cells. Additionally, CDla+ dendritic cells did not correlate with the other major cells that have been found to be important in COPD (macrophages, CD4 $\mathrm{T}$ cells and B cells). ${ }^{322} 23$ This also implies that Lactobacillus may not directly impact these cells in disease. However, since this study focused mostly on early COPD, it is possible that Lactobacillus do have an impact in later stages of the disease, but this study was not designed to examine this possible relationship.

There are some important limitations that need to be mentioned in this study. First, although there was a significant reduction in the $\mathrm{Vv}$ of macrophages and neutrophils between GD1-positive, and GD1-negative groups, the total number of positive samples was relatively small, and larger studies will need to be carried out in order to confirm these initial findings. Interestingly, the preliminary data set that was used for this study consisted of tissue samples from individuals other than those used in the early COPD data set and showed consistent data with respect to GD1 positivity: that there was a significant reduction in GD1 positivity as COPD increased in severity. Second, the tissue was obtained from patients with lung cancer, and even though tissue was obtained from areas well away from the tumour, the global bacterial load as well as the composition could have been affected. However, none of the percentage of total Lactobacillus values for the control, GOLD 1 and GOLD 2 groups are out of the range of what would be expected based on previous research on the bacterial microbiome in lung tissue. ${ }^{9}$ Third, although previous research has shown that there may be a difference between the bacterial microbiome when steroids are used ${ }^{24}$ there were very few individuals on steroids $(\mathrm{n}=3)$ in this patient population and, for this study, steroids probably had no effect on the reported findings. Fourth, although GD1 was analysed, reuterin was not directly measured in this study and the mechanism of action in which GD1 positivity exerts its anti-inflammatory effect may not be through this particular pathway. Further studies, aimed at investigating reuterin directly, will need to be performed to confirm that GD1 acts through this antibiotic to have anti-inflammatory effects within COPD.
Additionally, in vitro studies may be useful in elucidating cause and effect since these findings simply show interesting associations. Cause and effect is hard to differentiate from these types of studies and the GD1 Lactobacillus could simply be a bystander that disappears as these inflammatory processes take place.

As more information about how bacteria can influence and change our innate and adaptive immune system becomes known, it is becoming increasingly evident that many bacteria have beneficial effects that can positively influence our immune system. ${ }^{25}$ Although the effect is small, these results provide preliminary evidence of the potential benefit of GD1-positive Lactobacillus in small airway inflammation in COPD. Future studies may show that it could be possible to utilise Lactobacillus with the GD1 gene as a clinical intervention to help reduce inflammation or as a prophylaxis in those with mild and moderate COPD.

Contributors MAS performed and designed the experiments, performed data analysis and wrote the first draft; SU performed the experiments; MWE procured tissue samples; JCH conceived the study and made intellectual contributions; and RGH conceived the study, procured tissue samples and made intellectual contributions.

Funding The study was supported by Merck external studies agreement IIS 38970 (UBC \#F1038978), NIH \#HL084948 and CIHR \#CIF-97687. None of the agencies had any input into the study design; in collection, analysis and interpretation of the data; in writing of the report or in the decision to submit the report for publication.

Competing interests None.

Ethics approval University of British Columbia and St Paul's Hospital.

Provenance and peer review Not commissioned; externally peer reviewed.

Data sharing statement Extra data can be accessed via the Dryad data repository at http://datadryad.org/ with the doi:10.5061/dryad.pb830.

Open Access This is an Open Access article distributed in accordance with the Creative Commons Attribution Non Commercial (CC BY-NC 4.0) license, which permits others to distribute, remix, adapt, build upon this work noncommercially, and license their derivative works on different terms, provided the original work is properly cited and the use is non-commercial. See: http:// creativecommons.org/licenses/by-nc/4.0/

\section{REFERENCES}

1. Bourbeau J, Tan WC, Benedetti A, et al. Canadian Cohort Obstructive Lung Disease (CanCOLD): fulfilling the need for longitudinal observational studies in COPD. COPD 2014;11:125-32.

2. Mathers CD, Loncar D. Projections of global mortality and burden of disease from 2002 to 2030. PLoS Med 2006;3:e442.

3. Hogg JC, Chu F, Utokaparch S, et al. The nature of small-airway obstruction in chronic obstructive pulmonary disease. N Engl J Med 2004;350:2645-53.

4. Low TB, Greene CM, O'Neill SJ, et al. Quantification and evaluation of the role of antielastin autoantibodies in the emphysematous lung. Pulm Med 2011;2011:826160.

5. Sethi S, Evans N, Grant BJ, et al. New strains of bacteria and exacerbations of chronic obstructive pulmonary disease. $N$ Engl J Med 2002;347:465-71.

6. Erb-Downward JR, Thompson DL, Han MK, et al. Analysis of the lung microbiome in the "healthy" smoker and in COPD. PLOS ONE 2011;6:e16384.

7. Hilty M, Burke $\mathrm{C}$, Pedro $\mathrm{H}$, et al. Disordered microbial communities in asthmatic airways. PLOS ONE 2010;5:e8578.

8. Huang YJ, Kim E, Cox MJ, et al. A persistent and diverse airway microbiota present during chronic obstructive pulmonary disease exacerbations. OMICS 2010;14:9-59. 
9. Sze MA, Dimitriu PA, Hayashi S, et al. The lung tissue microbiome in chronic obstructive pulmonary disease. Am J Respir Crit Care Med 2012;185:1073-80.

10. Segal LN, Alekseyenko AV, Clemente JC, et al. Enrichment of lung microbiome with supraglottic taxa is associated with increased pulmonary inflammation. Microbiome 2013;1:19.

11. Talarico TL, Dobrogosz WJ. Purification and characterization of glycerol dehydratase from Lactobacillus reuteri. Appl Environ Microbiol 1990;56:1195-7.

12. Schaefer L, Auchtung TA, Hermans KE, et al. The antimicrobial compound reuterin (3-hydroxypropionaldehyde) induces oxidative stress via interaction with thiol groups. Microbiology 2010;156 (Pt 6):1589-99.

13. Bauer R, du Toit M, Kossmann J. Influence of environmental parameters on production of the acrolein precursor 3-hydroxypropionaldehyde by Lactobacillus reuteri DSMZ 20016 and its accumulation by wine lactobacilli. Int $J$ Food Microbiol 2010;137:28-31.

14. Casas IA, Dobrogosz WJ. Validation of the probiotic concept: Lactobacillus reuteri confers broad-spectrum protection against disease in humans and animals. Microb Ecol Health Dis 2000;12:247-85.

15. El-Ziney MG, Jakobsen M. Effectiveness of reuterin alone and in combination with nisin or other food contact surfaces sanitizers and cleaners for disinfection of stainless steel surfaces contaminated with Escherichia coli and Listeria innocua. J Food Agric Environ 2009;7:145-9.

16. Gosselink JV, Hayashi S, Elliott WM, et al. Differential expression of tissue repair genes in the pathogenesis of chronic obstructive pulmonary disease. Am J Respir Crit Care Med 2010;181:1329-35.

17. McDonough JE, Yuan R, Suzuki M, et al. Small-airway obstruction and emphysema in chronic obstructive pulmonary disease. $N$ Engl J Med 2011;365:1567-75.

18. Ferreira RB, Gill N, Willing BP, et al. The intestinal microbiota plays a role in Salmonella-induced colitis independent of pathogen colonization. PLOS ONE 2011;6:e20338.

19. Kinova Sepova H, Bilkova A. Isolation and identification of new lactobacilli from goatling stomach and investigation of reuterin production in Lactobacillus reuteri strains. Folia Microbiol (Praha) 2013;58:33-8.

20. Forsythe $P$, Inman MD, Bienenstock J. Oral treatment with live Lactobacillus reuteri inhibits the allergic airway response in mice. Am J Respir Crit Care Med 2007;175:561-9.

21. Karimi K, Inman MD, Bienenstock J, et al. Lactobacillus reuteri-induced regulatory $T$ cells protect against an allergic airway response in mice. Am J Respir Crit Care Med 2009;179: 186-93.

22. Paats MS, Bergen IM, Hoogsteden HC, et al. Systemic CD4+ and CD8+ T-cell cytokine profiles correlate with GOLD stage in stable COPD. Eur Respir J 2012;40:330-7.

23. Hogg JC. Pathophysiology of airflow limitation in chronic obstructive pulmonary disease. Lancet 2004;364:709-21.

24. Pragman AA, Kim HB, Reilly CS, et al. The lung microbiome in moderate and severe chronic obstructive pulmonary disease. PLOS ONE 2012;7:1-10.

25. Pflughoeft KJ, Versalovic J. Human microbiome in health and disease. Annu Rev Pathol 2012;7:99-122. 